\title{
METAFOR ATOM DALAM KARYA KRIYA TEKSTIL
}

\author{
Yesi Diana Putri dan Timbul Raharjo *)
}

\begin{abstract}
ABSTRAKSI
Atom merupakan partikel terkecil yang tidak dapat dibagi lagi. Segala sesuatu diseluruh dunia terdiri dari atom, baik manusia, hewan, tumbuhan, maupun benda mati. Model atom dari John Dalton, Joseph John Thomson, Ernest Rutherford, dan Niels Henrik David Bohr digunakan sebagai sumber ide yang akan divisualisasikan dalam bentuk karya kriya tekstil berupa busana. Penciptaan karya ini didasari dari latar belakang penulis yang menganggap sains dan seni dapat dikorelasikan untuk menjelaskan suatu isu melalui metafor atom. Dalam ilmu sains, bentuk model atom tidak dibuat untuk kepentingan estetika, namun didalamnya terdapat beberapa sifat dan bentuk visual yang menarik untuk dijadikan karya seni.

Metode penciptaan yang digunakan berupa pengumpulan data-data melalui studi pustaka atau observasi secara langsung, melakukan analisis data dengan menggunakan pendekatan estetika dan desain secara ergonomi. Metode selanjutnya adalah perwujudan karya yang dimulai dari perancangan, persiapan bahan, hingga mewujudkan karya untuk kemudian mengevaluasi kembali. Pengerjaan karya ini menggunakan teknik batik tulis, teknik cat pada kain, tie dye, serta sulam payet, aplikasi benang, dan sulam tapis sebagai finishing. Penciptaan karya seni ini juga diperkuat dengan beberapa teori seperti : teori atom, teori busana, dan teori quantum.

Hasil karya yang diciptakan berupa busana cassual wanita, dengan ornamen atom yang sudah digubahkan. Karya ini merupakan karya seni sekaligus bersifat fungsional yang dapat disesuaikan dalam penggunaannya. Diharapkan karya ini dapat memberikan inspirasi bagi masyarakat luas, ranah seni dan lembaga pendidikan, agar dapat menciptakan karya yang lebih inovatif dibidang seni, baik dari segi teknik maupun material khususnya seni kriya tekstil.
\end{abstract}

Kata Kunci: Atom, Busana, Ornamen

\section{ABSTRACT}

Atom is the smallest particle which can be divided into the smaller ones. The whole things in the world are consist of atom including human, animal, plant and the inanimate object. This work was inspired by the atom model from John Dalton, Joseph John Thomson, Ernest Rutherford, and Niels Henrik David Bohr. The tangible work was visualized in the textiles media as a cloth. This work is based on the writer's thought about the correlation of science and art which can figure out an issue from atom metaphor. In science, the form of atom can be used for the aesthetic field, but there are some interesting visual form inside the atom that can be explored as an art work.

The method used in this work were collecting the appropriate data through literature study, direct observation, and analizing the data using aesthetic approach also ergonomics design. The next step was embodiment the art work. It started with the plans, preparation the materials, its embodiment and evaluating. The technique of this work were using handmade batik, painting on the textile, tie dye, embroidery sequin, aplication thread, and embroidery tapis. The theory that used in this work are atom theory, fashion theory and quantum theory.

* Yessy Diana Putri (yessyidianaputri@yahoo.com) Mahasiswa Program Magister Penciptaan Pascasarjana Institut Seni Indonesia Yogyakarta, Hp: 085729001583. Timbul Raharjo (timbulksg@yahoo.com), Pengajar Program Magister Penciptaan Pascasarjana Institut Seni Indonesia Yogyakarta 
The art work result was an atom ornament cassual cloth which has new and vary form. This work is an art work also has a function depends on its user. The expectation of this work are giving the inspiration for the whole society, art field and the education institute. Thus, especially for the textile work, they can produce more creative art work, which is from its technique or its material.

Keywords : Atom, Cloth, Ornament

\section{PENDAHULUAN}

Atom merupakan partikel yang sangat kecil yang tidak dapat dibagi lagi bahkan hanya dapat dilihat dengan menggunakan alat yang disebut dengan scanning tunneling electron microscope stem. Seperti yang dikemukakan oleh Chang (2005:30), "Pada abad ke-5 SM, filsuf Yunani Democritus mengungkapkan keyakinannya bahwa semua materi terdiri atas partikel yang sangat kecil yang tidak dapat dibagi lagi, yang ia namakan atomos (berarti tidak dapat dibelah atau dibagi)". Menurut kamus besar bahasa Indonesia, atom merupakan unsur kimia terkecil setelah nuklir yang dapat berdiri sendiri dan dapat bersenyawa dengan yang lain.

Penulis mencoba memadukan antara sains yang merupakan ilmu pasti dengan seni yang dinamis. Menurut kamus besar bahasa Indonesia, sains adalah "pengetahuan sistematis yang diperoleh dari suatu observasi, penelitian, dan uji coba yang mengarah pada penentuan sifat dasar atau prinsip sesuatu yang sedang diselidiki, dipelajari". Penulis menangkap korelasi yang kuat antara sains dengan seni, dalam ranah ilmu pengetahuan, seni juga mengandung sifat-sifat keilmuan yang dimiliki oleh sains, yang sama-sama menggunakan metodemetode tertentu seperti observasi, penelitian, maupun uji coba, meskipun arah dan tujuannya sedikit berbeda. Seorang seniman akademis maupun non akademis dalam membuat karya juga melakaukan tahap-tahap yang sistematis. Selain itu, tidak ada bedanya dengan sains yang erat kaitannya dengan teknologi. Seni juga banyak melibatkan teknologi baik pada prosesnya maupun hasil. Pada penciptaan ini, penulis memilih atom sebagai sumber inspirasi karena ketertarikan pada segi visual model atom dari teori-teori yang ada, ketika digali lebih dalam, ternyata menimbulkan ketertarikan yang lebih dari sekedar bentuk. Atom yang dijadikan acuan dalam penciptaan ini bukanlah bentuk atom yang sesungguhnya, melainkan model atom berdasarkan teori yang dicetuskan oleh John Dalton, Joseph John Thomson, Ernest Rutherford, dan Niels Henrik David Bohr.

Seni kriya sudah hadir dalam kurun waktu yang panjang, dari zaman berburu dan meramu, kehidupan menetap dan tradisional, hingga zaman modern dan era global seperti sekarang ini. Peranan seni kriya tidak jauh dari kebutuhan masyarakat untuk memenuhi kebutuhan sehari-hari baik jasmani maupun rohani. Kebutuhan tersebut terus menerus diperlukan sehingga pembuatannya berlangsung secara turun temurun disertai dengan penyempurnaan, perubahan, dan perkembangan (Gustami, 2004:1). Konsep dan bentuk visual dari teori atom tersebut akan diterapkan dalam karya seni kriya tekstil berupa busana. Penulis menerapkan konsep atom pada busana dikarenakan penulis memiliki ketertarikan akan perkembangan dunia fashion yang semakin menunjukkan eksistensinya yang semula hanya bahan sandang untuk melindungi diri, berubah menjadi suatu mode yang mendunia. Tidak jarang busana juga digunakan untuk menunjukkan sebuah eksistensi dan status sosial seseorang sebagai konsumsi tanda yang kian menjadijadihal ini dikarenakan, busana juga dapat digunakan sebagai alat komunikasi 
seseorang seperti yang dikemukakan oleh Riyanto (2003:102) bahwa busana merupakan alat penunjang bagi seseorang dalam melakukan komunikasi. Busana juga mempunyai hubungan yang erat dengan seni kriya itu sendiri yaitu memiliki fungsi, pemenuh kebutuhan manusia, sekaligus bernilai estetis.

Bentuk model atom tersebut akan digubah kembali oleh penulis, sehingga mempunyai nilai estetika yang lebih dari bentuk aslinya. Seorang seniman tidak hanya memindahkan suatu bentuk pada sebuah objek semata, namun juga mengembangkannya lagi sesuai dengan apa yang ingin disampaikan lewat karya tersebut. Model atom ini akan diterapkan sebagai ornamen yang menghiasi busana, seperti penjelasan dari Gustami (2008:3) bahwa ornamen berasal dari bahasa latin yaitu ornare yang berarti menghiasi.

Adapun tujuan dari penciptaan ini adalah menuangkan hasrat berkesenian dan kreativitas, mengembangkan dunia seni kriya tekstil dengan menciptakan karya busana yang menggunakan konsep model atom sebagai sumber penciptaan, memadukan antara sains sebagai ilmu pasti ke dalam karya seni.

\section{Landasan Teori dan Metode Penciptaan}

Metode dalam pembuatan karya memiliki perananan penting untuk menjadikan proses berkarya lebih sistematis, selain itu, teori yang tepat akan membantu dalam membedah permasalahan di dalam karya tersebut. Teori mengenai atom diperlukan untuk mengetahui seluk beluk sejarah atom, serta untuk mendalami konsep dan bentuknya, kemudian didekonstruksi sesuai dengan apa yang ingin disampaikan oleh seniman. Untuk menemukan teori mengenai atom diperlukan proses panjang yang melibatkan banyak filsuf dan pemikir dari berbagai macam negara.

Salah satu konsep ilmiah yang paling tua adalah mengungkapkan bahwa semua benda dapat dipecah menjadi partikel-partikel yang dapat dibagi lebih lanjut. Filosof Yunani Demicritus (kira-kira 460-370 sebelum Masehi) menyatakan bahwa partikelpartikel ini dalam keadaan bergerak tetap, tetapi dapat bergabung bersama-sama menjadi gabungan yang stabil (Sastrohamidjojo, 2008:3).

Bila dilihat dengan alat scanning tunneling electron microscope stem, atom berbentuk menyerupai bulatan-bulatan yang tersusun dengan kerapatan tertentu. Namun hal ini juga dipengaruhi oleh jenis unsur yang dilihat, karena setiap unsur memiliki nomor atom yang berbeda sehingga susunan dan kerapatannya juga berbeda satu sama lain. Menurut kamus bahasa Indonesia, atom merupakan unsur kimia terkecil setelah nuklir yang dapat berdiri sendiri dan dapat bersenyawa dengan yang lain. Purba juga berpendapat bahwa, atom berasal dari bahasa Yunani yaitu atomos (a, tidak + tomos, dipecah), maka atom berarti tidak dapat dipecah atau tidak dapat dibagi lagi (2006:18).

Teori yang kedua adalah teori tentang busana, menurut Riyanto(2003:2), busana dalam arti umum adalah bahan tekstil atau bahan lainnya yang sudah dijahit atau belum dijahit yang dipakai atau disampirkan untuk menutup tubuh seseorang termasuk dengan aspek-aspek yang menyertainya termasuk milineris dan aksesoris.

Teori selanjutnya adalah teori Quantum yang digunakan untuk membuka pemahaman mengenai konsep atom yang akan dipadukan dengan busana. Marianto (2015:45-46) dalam buku Art and Levitation menyebutkan teori Quantum merupakan teori yang menyatakan bahwa pada level sub-atomik semua materi dan energi pada saat yang sama dapat menjadi sebuah partikel maupun memiliki sifat sebagai gelombang. Marianto juga menerangkan bahwa dalam cakrawala pemahaman ini seni akan dilihat, ditelaah, ditafsirkan, dikaji, dan dimaknai melalui pemahaman Quantum. 
Artinya bahwa karya seni atau fenomena seni apa saja dapat dilihat sebagai dualitas. Penulis menggunakan teori Quantum karena penulis juga memadukan dua hal yang berbeda pada karyanya, yaitu atom yang diterapkan pada busana sebagai karya seni. Atom yang sejatinya merupakan teori dari ilmu sains, kemudian dipandang secara dualitas sebagai karya seni.

Metode penciptaan yang digunakan dalam penciptaan karya seni ini adalah dengan mengumpulkan data yang berkaitan dengan atom dan busana kemudian data tersebut diolah kembali dan dianalisis untuk mendapatkan kesimpulan dan data yang baik, sehingga dapat mendukung karya yang akan dibuat. Data yang terkumpul kemudian dibuat rancangan yang sesuai untuk diwujudkan kedalam sebuah karya seni. Teknik yang digunakan dalam pembuatan karya ini berupa batik tulis, Tie Dye, payet, aplikasi kain, sulam tapis, dan cat.

Penciptaan karya seni ini mengacu pada tahapan-tahapan yang digunakan Gustami (2004:29), yang menyebutkan bahwa dalam menciptakan karya seni kriya dilakukan melalui tiga tahapan yaitu eksplorasi yang berupa pengumpulan datadata untuk kemudian dianalisis yang akan dijadikan acuan, perancangan yang berupa memvisualisasikan ide ke dalam gambar yang mengacu pada data atau gambar yang sudah diperoleh dan dari data yang sudah dianalisis, tahap ketiga yaitu perwujudan. Perwujudan karya seni dilakukan dengan urutan kerja yang baik seperti mengumpulkan data, menganalisis, sketsa, desain, mengumpulkan alat dan bahan, hingga mencapai proses kerja perwujudan karya, kemudian mengevaluasi kembali. Hal ini dilakukan agar proses pengerjaan terlaksana dengan baik, oleh karena itu diperlukan langkah-langkah yang tepat.

\section{Sintesis}

Teori dari Bohr merupakan teori yang sudah disempurnakan dari teori penemu atom sebelumnya yaitu disebutkan oleh Purba (2006:18-21), John Dalton menemukan teori atom yang pertama sekitar tahun 1803-1807, namun pada masanya Dalton hanya menyimpulkan teorinya dari data eksperimen yang ada dan tidak pernah mengamati keberadaan atom. Oleh karena itu, teori atom Dalton hanyalah sebuah model dari atom yang sebenarnya tidak dapat dilihat dengan mata biasa. Purba kembali menjelaskan (2006:23-25) elektron ditemukan oleh Joseph John Thomson pada 1900 , penemuan elektron dilakukan dengan percobaan-percobaan hantaran listrik melalui tabung hampa. Pada teori atom Thomson, Dalton yang sebelumnya menyatakan bahwa atom merupakan partikel yang tidak terbagi tidak diterima lagi. Pada 1900 Thomson mengajukan model atom yang menyerupai roti kismis yaitu atom terdiri dari muatan positif yang didalamnya tersebar elektron bermuatan negatif dan secara keseluruhan atom dapat dikatakan bersifat netral. Penjelasan Purba mengenai atom Ernest Rutherford pada tahun 1911, Rutherford menjelaskan penghamburan sinar alfa dan mengajukan gagasan mengenai inti atom. Menurut Rutherford sebagian besar dari massa dan muatan posistif atom terkonsentrasi pada bagian pusat inti, namun kelemahan teori Rutherford yaitu tidak menjelaskan mengapa atom tidak jatuh pada inti (2006:27-29).

Menurut Brady dalam Maun, Anas, dan Sally, Niels Bohr ahli fisika bangsa Denmark memilih hidrogen sebagai model untuk teorinya. Hal ini dikarenakan hidrogen mempunyai atom yang paling sederhana yaitu satu proton dan satu elektron kemudian hal ini menghasilkan spektrum atom yang paling sederhana. Teori Bohr mengemukakan model sistem solar (solar system) untuk atom hidrogen, dimana elektron dapat mengelilingi inti atom dengan orbit Elektron dan proton saling tarik menarik sehingga bertambah besar ortbitnya, bertambah besar pula energi elektronnya. (1999:282). Berikut adalah model atom Dalton sampai dengan Bohr 
yang sekaligus digunakan sebagai data acuan berupa gambar:

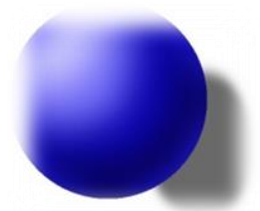

Gambar. 1 Model Atom Dalton

(Sumber:https://hyenia.files.wordpress.com/2012/04 /Dalton-e1335359815588.jpg?w=500\&h=500, 14-062017, 10:54)

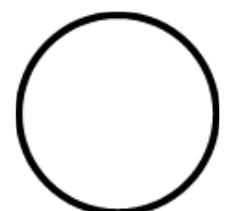

Gambar. 2 Model Atom Dalton dalam Dua Dimensi (Sumber: https://www.siyavula.com/science/grade10/04-the-atom/pspictures/46426eb0ac77e549 b392264722e54fc. png, 14-06-2017, 10:58)

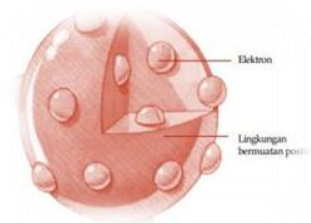

Gambar. 3 Model Atom Thomson (Sumber:https://iO.wp.com/kimiadasar.com/wpcontent/uploads/2015/10/model-atomthomson.jpg?resize $=300 \% 2 \mathrm{C} 230,14-06-2017,11.07$ )

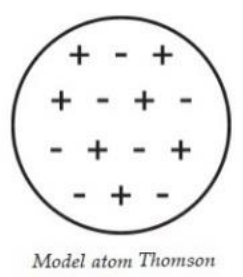

Gambar. 4 Model Atom Thomson dalam Dua Dimensi (Sumber:http://fisikazone.com/wp-

content/uploads/2014/09/Model-Atom-Thomson.jpg, 14-06-2017, 11.10)

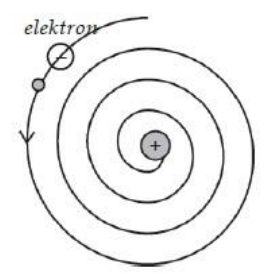

Gambar. 5 Pola Model Atom Rutherford (Sumber:http://fisikazone.com/wpcontent/uploads/2014/09/Lintasan-Spiral-ElektronAthom-Rutherford.jpg, 14-06-2017, 11.33)

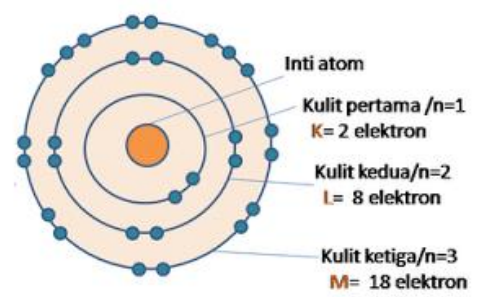

Gambar. 6 Pola Model Atom Bohr

(Sumber:https://1.bp.blogspot.com/-

1h2JCvyfQBs/VsBXiwIZOWI/AAAAAAAAAEg/j8XBRayTJ pc/s1600/teori\%2Batom\%2Bbohr.png, 14-06-2017, 11.43) Rutherford.jpg, 14-06-2017, 11.33)

Gambar atom di atas merupakan model atom dari John Dalton, Joseph John Thomson, Ernest Rutherford, dan Niels Henrik David Bohr dari tampak tiga dimensi hingga skema berbentuk dua dimensi yang dikutip dari beberapa blog. Penulis menggunakan sumber ide keempat dari pencetus teori tersebut karena satu sama lain memiliki keterkaitan yang erat dari mulai bentuk, pola, hingga penyempurnaan satu sama lain dalam sejarah perkembangannya. Gambar tersebut cukup jelas untuk dijadikan data acuan dalam membuat karya. Penulis menggubahkan kembali bentuk visual dari teori-teori tersebut untuk dapat menjelaskan isu tertentu melalui metafor atom. Bila dianalisis dari segi visual, model atom berdasarkan teori tersebut merupakan bangun datar dua dimensi dan tiga dimensi yaitu lingkaran dan bentuk bola. Oleh karena itu, penulis mengembangkan kembali tidak hanya dalam bentuk bulat dan lingkaran saja, namun juga bentuk kubus yang merupakan sama-sama masuk dalam kategori bangun datar.

Metafor berasal dari kata metafora yang berarti menyerupai atau mengkiaskan, seperti yang dikemukakan oleh Budiman, (2011:7), di dalam Websiter's New International Dictionary metafora didefinisikan secara tipikal sebagai sebuah kiasan yang menggunakan sepatah kata atau frase yang mengacu pada objek atau tindakan tertentu untuk menggantikan kata atau frase yang lain, sehingga tersarankan suatu kemiripan atau analogi di antara 
keduanya (a figure speech in which a word or a phrase denoting one kind of object or action is used in place of another to suggest a likeness or analogy between them). Budiman melanjutkan, dikatakan tipikal karena pada umumnya teori-teori mengenai metafora sejak zaman Aristoteles sampai pada teori semiotika yang mutakhir masih berkutat pada konsep yang menjadi kata kunci yaitu kemiripan atau analogi yang diperoleh dari sebuah perbandingan atas dua hal yang berbeda. Sejalan dengan pengertian tersebut, salah satu teori yang paling populer tentang metafora merumuskan dengan sangat singkat sebagai perbandingan tersirat diantara dua hal.

Hubungannya dengan seni kriya, metafor, fungsi dan estetika, busana dapat menjadi simbol atau media komunikasi secara visual seperti pada karya ini. Busana dapat mewakili untuk meraih semua hal yang ingin penulis sampaikan lewat karyanya, oleh karena itu, penulis memilih busana sebagai media yang dianggap paling tepat. Selain itu, menurut Simmel dalam Ritzer (2012:277) menyebutkan bahwa di dalam fesyen semua mengandung tendensitendensi antitesis. Begitu pula karya yang penulis buat, namun busana yang penulis buat lebih mengarah pada seni yang dapat difungsikan atau dipakai, bukan menggaris besarkan pada segi fungsional. Busana yang menjadi acuan adalah busana dari Delpozo dan dokumentasi pribadi penulis sebagai berikut:

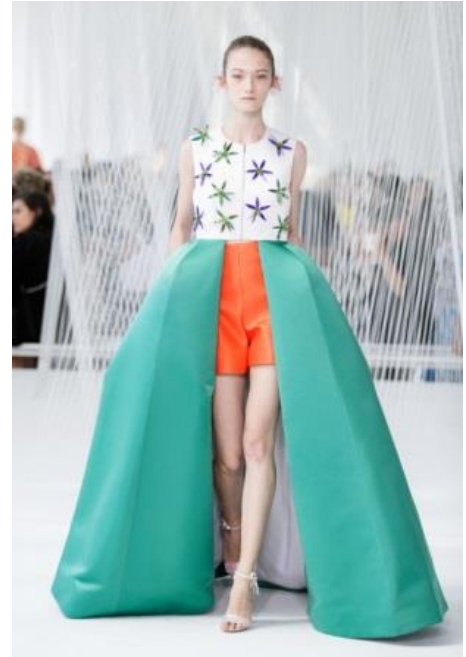

Gambar. 7 Karya Delpozo (inspirasi rok menggembung dari karya I)

(Sumber:https://theecstaticflash.files.wordpress.com /2016/09/delpozo_ss17-look-37.jpg?w=500\&h=751, 14-06-2017, 14.52)

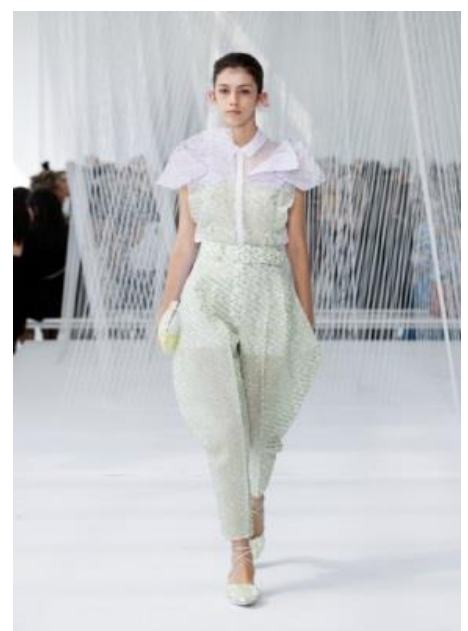

Gambar. 8 Karya Delpozo (inspirasi celana transparan bertumpuk dari karya II)

(sumber:https://theecstaticflash.files.wordpress.com /2016/09/delpozo_ss17-look-29.jpg? $w=500 \& h=750$, 14-06-2017, 14.56) 


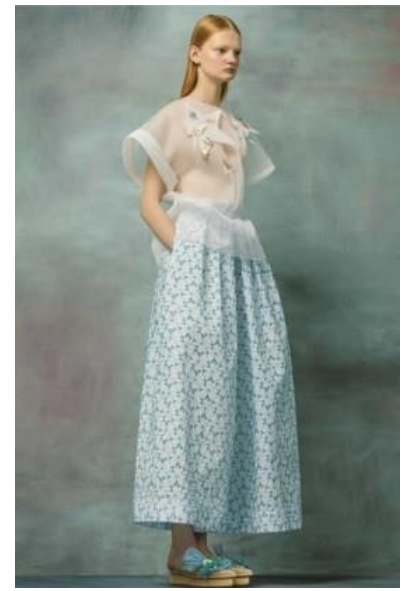

Gambar. 9 Karya Delpozo (inspirasi bentuk lengan dari karya I dan III)

(Sumber:https://leveridgedlives.files.wordpress.com/ 2016/06/029-delpozo-resort-

17_426x639.jpg?w=275\&h=413, 14-06-2017)

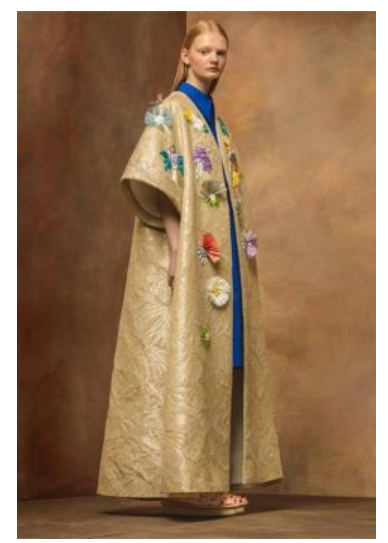

Gambar. 10 Karya Delpozo (inspirasi bentuk outer dan lengan karya III)

(Sumber:http://www.fashiontrendsetter.com/v2/wpcontent/uploads/2017/01/Delpozo-Resort-2017-

11.jpg, 14-06-2017)

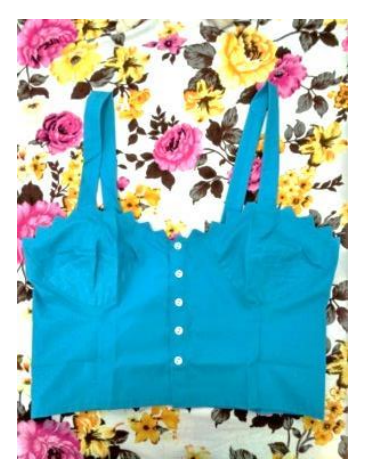

Gambar. 11 Kutang Nenek (inspirasi bentuk inner karya III)

(Sumber: Dokumentasi Penulis)
Dari data acuan berupa gambar di atas, kemudian penulis membuat desain karya sebagai berikut:

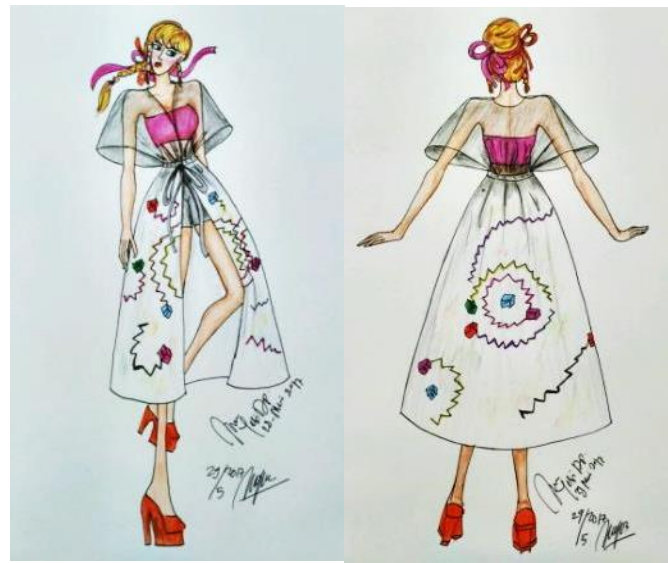

Gambar. 12 Desain Karya I (depan dan belakang) (Desain : Yesi Diana P.)

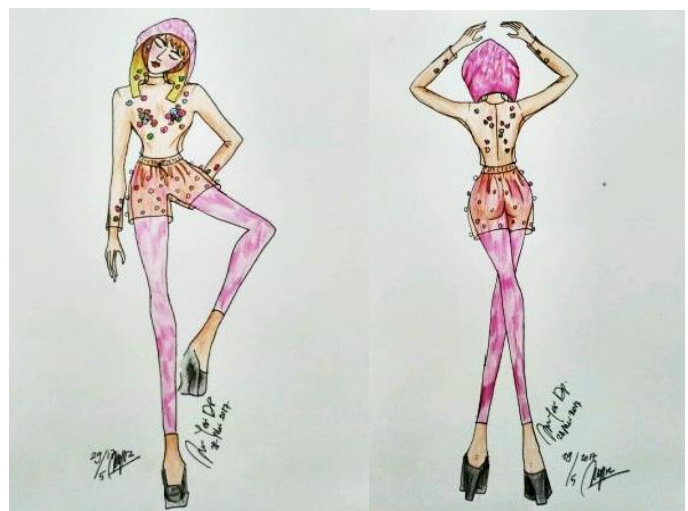

Gambar. 13 Desain Karya II (depan dan belakang) (Desain : Yesi Diana P.)

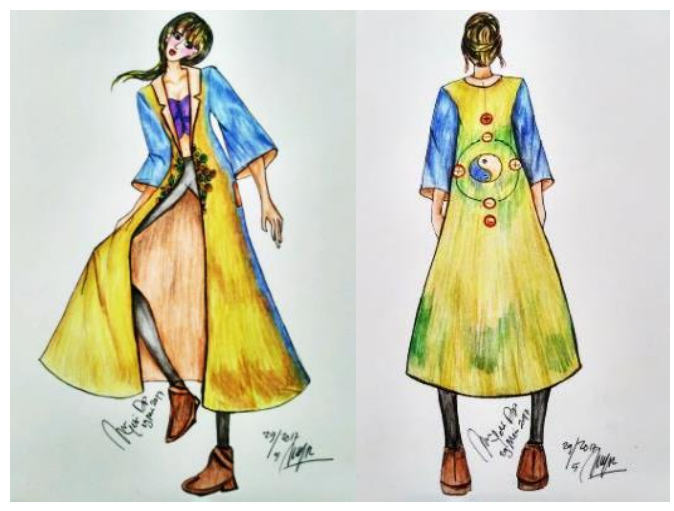




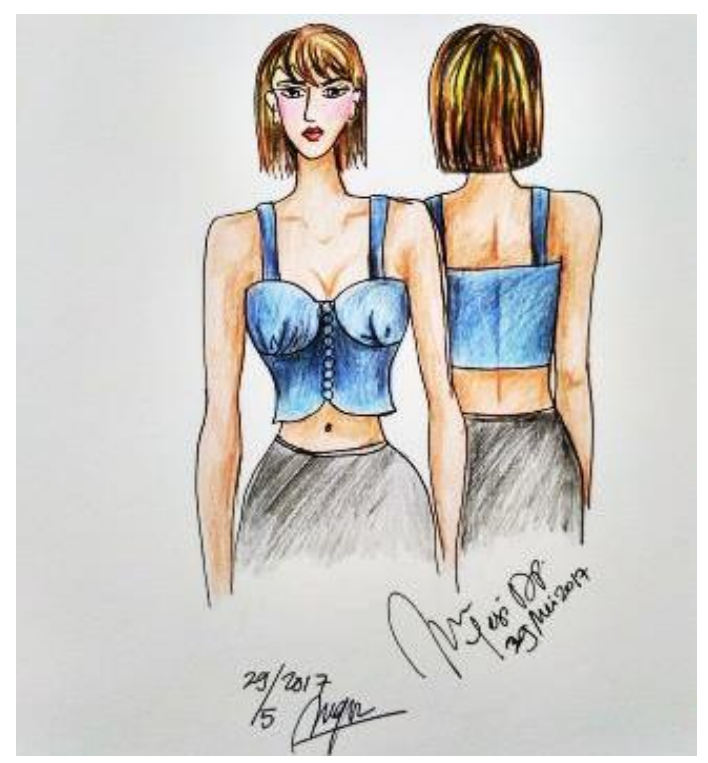

Gambar. 14 Desain Karya III

(depan, belakang, dan inner)

(Desain : Yesi Diana P.)

Bahan baku dalam pembuatan karya ini adalah dari material tekstil sintetis dan non sintetis. Pemiliham bahan baku tertentu berfungsi untuk memberikan efek dan kesan tertentu pada karya sesuai apa yang diharapkan penulis. Material non sintetis digunakan untuk bagian yang menggunakan teknik batik pada pengerjaannya, hal ini dilakukan agar pewarna dapat masuk dengan baik pada pori-pori kain. Selain batik, teknik dalam pembuatan karya ini berupa tie dye, teknik cat pada kain, sulam payet, aplikasi benang dalam rajut dan sulam tapis. Bentuk yang dihasilkan dalam penciptaan karya ini berupa busana cassual yang menonjolkan sisi feminim dengan warnawarna berani dan cerah. Warna-warna dalam pembuatan karya ini bervariasi, hampir semua warna digunakan karena untuk menggambarkan perjalanan hidup manusia dengan permasalahanpermasalahan yang kompleks.

\section{Hasil dan Pembahasan}

Karya I : karya ini menceritakan perjalanan hidup manusia di dalam rahim. Dimana perempuan diciptakan dengan tubuh yang luar biasa, memiliki wadah yang kokoh untuk melindungi dan melahirkan anak manusia. Reaksi fisi nuklir adalah tumbukan dua atom yang kemudian terpecah membentuk atom baru dengan muatannya sendiri. Diibaratkan seperti anak manusia yang terbentuk dari sperma dan sel telur dari dua orang yang berbeda, tercipta individu baru yang memliki sifat tidak sepenuhnya mengikuti ayah dan ibunya, dengan kata lain ia tetap menjadi dirinya sendiri dengan muatannya sendiri.
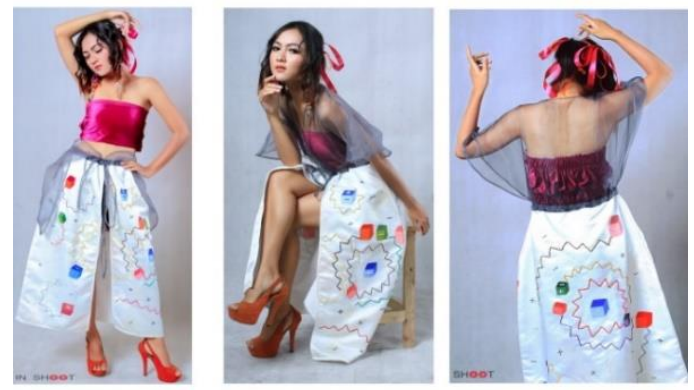

Gambar. 15 Karya I Judul : Reaksi Fisi Nuklir, Ukuran : Small, Teknik : Cat, Payet,Sulam Tapis, Bahan : Kain Organdi, Kain Bridal, Kain Bludru, Model: Pebriarti (Kiki)

(Foto : Budi Setya, 2017)
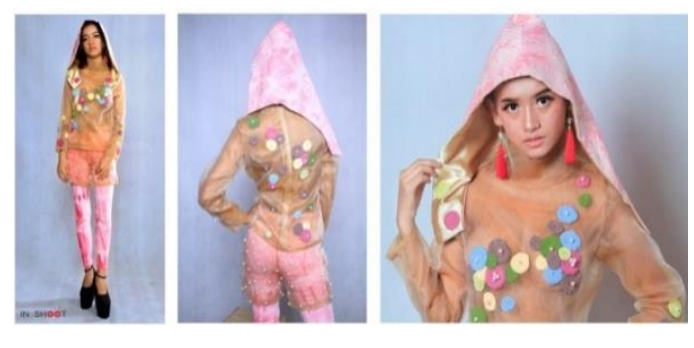

Gambar. 16 Karya II Judul : Elektron Valensi, Ukuran : Small, Teknik : Rajut, Tie Dye, dan Manik-Manik, Bahan : Kaos (Kain Spandex), Kain Organdi, Kain Velvet, dan Kain Dolbi, Model: Ariska Arlinda

(Foto : Budi Setya, 2017)

Karya II: sebagaimana elektron valensi yang harus mencari pasangannya untuk menjadi netral, sosok perempuan juga harus dapat mengendalikan dirinya, melepas muatan-muatan atau sisi negatif dari dirinya, mencari energi positif untuk menetralkan dirinya. Perempuan harus tegar dan dapat menjadi daya tarik dari hal-hal positif yang baik untuk dirinya. 

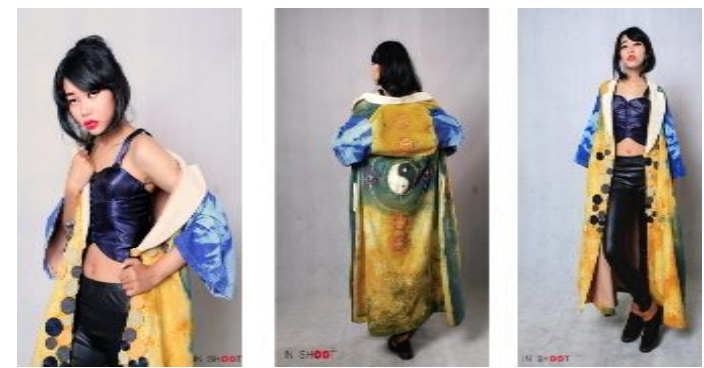

Gambar. 17 Karya III Judul : Kovalen, Ukuran : Small, Teknik : Tie Dye, Batik, Aplikasi Kain, dan Sulam Tapis, Bahan : Kanvas, Kain Zetta, Kain Kulit Sintetis, dan Kain Katun Imma, Model: Iwang Yudita Fajar (Foto : Budi Setya, 2017)

Karya III: karya yang berjudul "Kovalen" ini menceritakan tentang keseimbangan. Menyatakan hakikat manusia terlebih perempuan harus bisa menyeimbangkan dirinya antara emosi jiwa dan perasaan. Pada dasarnya perempuan sulit untuk memakai logikanya dibandingkan perasaan. Tidak hanya itu, keseimbangan yang dimaksud juga merujuk pada seluruh manusia yang harus selaras dengan alam. Pada dasarnya alam ini adalah sesuatu yang seimbang seperti Yin dan Yang. Maka manusia harus selaras dengan alam semesta untuk mencapai kehidupan yang tentram. Karya ini menggambarkan sosok seorang ibu.

Karya yang penulis buat secara keseluruhan menggunakan pewarna sintetis berupa naphtol dan indigosol. Naphtol yang digunakan adalah AS dan Biru BB, AS-G dan Biru BB, kemudian indigosol warna pink. Selain itu, dalam teknik cat menggunakan cat akrilik. Kesesuaian desain dengan hasil jadi karya merupakan hal yang kadang sulit dicapai. Dalam berproses, seorang pelaku seni selalu mengembangkan kreativitasnya. Oleh karena itu desain biasanya hanya dijadikan sebagai acuan garis besar dari sebuah karya. Ketika dalam desain sudah nampak indah, namun pada kenyataannya ada sesuatu yang janggal atau kurang. Perlu berulang-ulang dan terus mencoba agar sesuai dan nyaman untuk dipakai. Untuk mendesain terkadang jauh lebih mudah dibandingkan saat praktik merealisasikannya. Untuk itulah evaluasi terus menerus diperlukan seorang perupa pada saat berkarya. Karya tersebut juga banyak menceritakan mengenai isu-isu dalam kehidupan manusia yang kompleks, namun penulis lebih cenderung menonjolkan kehidupan seorang perempuan dengan lebih banyak menggunakan warna-warna cerah kemudian bentuk busana yang feminim.

Riset yang dilakukan oleh penulis adalah dari segi meterial dan analisis pada data acuan baik secara visual maupun teori. Penulis mencoba menggunakan kanvas pada salah satu karyanya yaitu pada karya III. Kanvas yang biasanya digunakan sebagai media untuk melukis kali ini digunakan sebagai meterial dalam membuat busana. Kanvas ini kemudian dibatik dan diwarnai dengan pewarna tekstil. Kanvas terdiri dari beberapa jenis, ada yang dapat menyerap warna dengan baik dan ada yang tidak. Penulis memilih kanvas dari material katun sehingga dapat meresap warna dengan baik. Kanvas cenderung lebih tebal dari pada kain yang sudah umum dibuat busana. Cukup sulit untuk membatik karena harus bolak balik, dalam proses nglorod juga harus sabar karena lilin tidak begitu saja dapat terlepas dari serat kain, kemudian karena ketebalannya tersebut, sehingga menimbulkan daya resap yang lumayan kuat. Oleh karena itulah diperlukan pula pewarna yang lebih banyak. Pada material yang tidak lazim digunakan seperti ini perlu perlakuan khusus sehingga dapat menghasilkan karya yang baik.

\section{Penutup}

Dalam berkesenian, ide inspirasi dapat hadir dari mana saja. Begitu pula memadukan dua ilmu pengetahuan yang berbeda, yaitu sains dengan seni. Ide dan kreativitas seorang seniman tidak terbatas oleh sekat-sekat ilmu pengetahuan. Proses pembuatan karya tentu saja mengalami beberapa kendala, diantaranya adalah kesesuaian antara desain dengan karya. Perubahan spontanitas wajar terjadi, karena proses berfikir seorang seniman terus 
berkembang dengan respon-respon yang baru, segar dan seslalu bergerak dengan kreativitas yang spontan. Penggambaran yang baik pada desain belum tentu dapat menghasilkan karya yang luar biasa pada kenyataannya, oleh karena itu, kreativitas yang terus berkembang menjadi hal yang paling penting digunakan oleh setiap seniman. Kendala teknis yang terjamerupakan hal yang wajar, hal itu tergantung bagaimana seorang seniman dapat merespon itu dengan baik. metode dalam penciptaan juga diperlukan sebagai acuan dan membantu agar seorang seniman dapat bekerja dengan sistematis, meskipun demikian, masing-masing pelaku seni tetaplah mempunyai metodenya masingmasing.

\section{DAFTAR PUSTAKA}

Brady, James E. (1998), General Cemistry Principles \& Structure, Kimia Universitas Azas \& Struktur (Jilid 1Edisi ke-5), Sukmariah Maun, Kamianti Anas, Tilda S. Sally. (1999), Binarupa Aksara, Jakarta.

Budiman, Kris. (2011), Semiotika Visual; Konsep, Isu, dan Problem Ikonitas, Jalasutra, Yogyakarta.

Chang, Raymond. (2003), General Chemistry: The Essential Concepts, Kimia Dasar: Konsep-Konsep Inti, terjemahan Departemen Kimia, Institut Teknologi Bandung: Muhamad Abdulkadir M., dkk. (2005), Erlangga.

Departemen Pendidikan Nasional. (2011), Kamus Besar Bahasa Indonesia Edisi Keempat, PT. Gramedia Pustaka Utama, Jakarta.

Gustami, SP. (2004), Proses Penciptaan Seni Kriya, Untaian Metodologis, Program Penciptaan Seni Pasca Sarjana ISI Yogyakarta, Yogyakarta. . (2008), Nukilan Seni Ornamen Indonesia, Jurusan Kriya Fakultas Seni Rupa Institut Seni Indonesia Yogyakarta, Yogyakarta.

Marianto, Dwi. (2015), Art \& Levitation, POHONG CAHAYA, Yogyakarta.
Purba, Michael. (2006), Kimia untuk SMA Kelas $X$, Erlangga.

Ritzer, George. (2011), Teori Sosiologi; Dari Sosiologi Klasik Sampai Perkembangan Terakhir Postmodern, Terjemahan: Saut Pasaribu, Rh. Widada, Eka Adinugraha (2012), Pustaka Pelajar, Yogyakarta.

Riyanto, Arifah A. (2003), Teori Busana, Yapemdo, Bandung.

Sastrohamidjojo, Hardjono. (2008), Kimia Dasar, Gadjah Mada University Press, Yogyakarta.

\section{Webtografi}

https://hyenia.files.wordpress.com/2012/0 4/dalton-

e1335359815588.jpg?w=500\&h=500, 1406-2017, 10:54

https://i0.wp.com/kimiadasar.com/wpcontent/uploads/2015/10/model-atomthomson.jpg?resize $=300 \% 2 \mathrm{C} 230$, 14-062017, 11.07

http://fisikazone.com/wpcontent/uploads/2014/09/Model-AtomThomson.jpg, 14-06-2017, 11.10

http://fisikazone.com/wpcontent/uploads/2014/09/Lintasan-SpiralElektron-Athom-Rutherford.jpg, 14-062017, 11.33

https://1.bp.blogspot.com/1h2JCvyfQBs/VsBXiwIZOWI/AAAAAAAAAEg j8XBRayTJpc/s1600/teori\%2Batom\%2Bbohr .png, 14-06-2017, 11.43

https://theecstaticflash.files.wordpress.com /2016/09/delpozo_ss17-look-

37.jpg? $w=500 \& h=751,14-06-2017,14.52$

https://theecstaticflash.files.wordpress.com /2016/09/delpozo_ss17-look29.jpg? $w=500 \& h=750,14-06-2017,14.56$

https://leveridgedlives.files.wordpress.com /2016/06/029-delpozo-resort-

17_426x639.jpg? $w=275 \& h=413,14-06-2017$ http://www.fashiontrendsetter.com/v2/wp -content/uploads/2017/01/Delpozo-Resort2017-11.jpg, 14-06-2017 